\title{
HEALTH SEEKING BEHAVIOR TOWARDS MINOR AILMENTS AMONG UNIVERSITY STUDENTS IN MALAYSIA
}

\author{
LI-YING TAN, SIEW SIANG CHUA \\ School of Pharmacy, Faculty of Health and Medical Sciences, Taylor's University, Subang Jaya, Selangor, Malaysia \\ Email: siewsiang.chua@taylors.edu.my
}

Received: 31 Aug 2020, Revised and Accepted: 18 Dec 2020

\begin{abstract}
Objective: This study was conducted to identify the types of minor ailments encountered by university students in Malaysia and the action taken in response to these ailments.

Methods: A cross-sectional study was conducted on undergraduate students from the various faculties in a major private and a public university in Malaysia. A researcher stationed at different areas of the universities to recruit respondents. If the student agreed to participate, he/she would sign a consent form and then self-filled a structured questionnaire.

Results: Of the 856 respondents included in this study, $68.6 \%$ were female and $60.6 \%$ rated their health status as 'good' or 'very good'. During the one month period prior to the study, $87.4 \%$ of the respondents encountered at least one minor ailment. The five most common minor ailments encountered were headache (58.1\%), common cold (42.8\%), sore throat (42.6\%), cough (40.3\%) and back pain $(27.6 \%)$. The main actions taken were rest at home and self-medication. The most common drug used for the treatment of minor ailments was paracetamol (49\% of the respondents). Other drugs were used by less than $10 \%$ of the respondents. The main source of information was from parents (63.7\%), followed by doctors (59.9\%), internet (57.9\%), pharmacists (33.9\%) and friends (33.5\%).
\end{abstract}

Conclusion: Headache is more common among university students compared to the general population. Further studies are required to understand the cause of headache among this population.

Keywords: Health behavior, Medication, Minor ailment, Self-medication, Undergraduates

(c) 2021 The Authors. Published by Innovare Academic Sciences Pvt Ltd. This is an open access article under the CC BY license (https://creativecommons.org/licenses/by/4.0/) DOI: https://dx.doi.org/10.22159/ijpps.2021v13i2.39596. Journal homepage: https://innovareacademics.in/journals/index.php/ijpps.

\section{INTRODUCTION}

Minor ailments are defined as acute health conditions, which require only minimal medical attention and simple medication(s) to treat the symptoms [1]. In addition, they are often self-limiting; that is, they will resolve by itself over a short period, even without any treatment. The most common minor ailments reported were cough, fever, sore throat and upper respiratory tract infections [1, 2].

University students may encounter minor ailments frequently due to unhealthy lifestyles, poor eating habits and stress $[3,4]$. Studies in various countries found that headache, flu and fever were the most commonly encountered minor ailments by university students [5-7]. Subsequent action taken by individuals to relieve the unpleasant symptoms of minor ailments included seek medical advice from a doctor or a pharmacist, use home remedies or medications available at home, rest or do nothing about the symptoms. It was found that self-medication had been widely practiced among both medical and non-medical students but more prevalent among medical students $[6,8]$. University students utilized a range of health information from the Internet, which allowed them to self-diagnose and selfmedicate [9]. They might also consult their parents or friends, treat the minor ailment according to previous experiences, or ignore the ailment as it would resolve by itself [10-12].

Thus far, most of the studies on minor ailments and health-seeking behavior among university students were conducted in developing and under-developed countries, but such studies are still scarce in Malaysia. However, such studies will provide information for health care providers to educate and help this population group to better cope with their minor ailments and hence, minimize its impact on their academic performance and quality of life. Therefore, the present study aimed to identify the types of minor ailment encountered by university students in Malaysia and the action taken to treat these ailments.

\section{MATERIALS AND METHODS}

A cross-sectional study was conducted on university students from various faculties in a major private (University A) and a public university (University B) in Malaysia. This study has been approved by the Medical Ethics Committee of University Malaya Medical Centre (Ref. No. MECID NO.: 201511-1829) and the Human Ethics Committee of Taylor's University (Ref. No. HEC 2017/022).

Any undergraduate students who were registered in the two universities at the time of the study and were able to read and understand English, were requested to participate in the study. Preuniversity students (such as those in Foundation and Diploma courses) and postgraduate students (Master or Doctor of Philosophy candidates) were excluded.

Medical-related students were those from the faculties related to health and medical sciences; while non-medical related included students from other faculties in the two universities, such as Arts and Social Sciences.

Both University A and B have more than 10,000 undergraduate students. The sample size required was calculated using Raosoft sample size calculator (http://www.raosoft.com/samplesize.html). With $95 \%$ confidence level, $5 \%$ margin of errors and assuming that $50 \%$ of the students had a minor ailment during the past one month, the sample size required was at least 373 students from each university.

A self-filled questionnaire was developed based on the literature and used to collect data in this study. It consisted of 21 items in four parts: (1) social-demographic characteristics of the respondent, (2) health status and medical history, (3) a list of minor ailments and options on health-seeking behavior, and (4) the management of minor ailments, which included the use of medications and sources of health information.

A pilot study was conducted on 25 and 20 undergraduate students from University A and B, respectively, to obtain feedback on the clarity of the questionnaire and to test the feasibility and practicability of the study procedure. Minor changes were done on 
the questionnaire based on comments of the respondents and the results of the pilot study.

The number of respondents recruited from each faculty was proportional to the number of students in the faculty in relation to the total student population in each of the university. A researcher stationed herself at different common areas of the universities such as the Student Centre, library, cafeteria, entrance to the faculties or schools, outside computer rooms and lecture theatres, to recruit the students. The researcher approached any student based on convenience sampling and requested the student to participate in the study. The researcher explained the study objectives and procedure to the student. If the student agreed to participate, he/she would sign an informed consent form. After that, the student was given the structured questionnaire to self-fill and an information sheet about the study for his/her own reference. On completion of the questionnaire, the student returned it to the researcher, who checked it to ensure that the questionnaire has been answered fully.

All data collected were entered and analyzed using the Statistical Package for the Social Science (SPSS) software for windows, version 21.0 (Armonk, NY: IBM Corp.). Descriptive statistics such as frequencies and percentages were generated for all variables.

\section{RESULTS}

A total of 856 respondents were included in this study. The demographic data of these respondents are as shown in table 1 . Seventy-four respondents $(8.6 \%)$ reported that they have immediate family members who worked as health care professionals. Sixty-five respondents (7.6\%) had chronic illnesses and the most commonly reported chronic illnesses were asthma $(n=26)$, and eczema $(n=18)$.

Table 1: Characteristics of the respondents

\begin{tabular}{|c|c|c|c|}
\hline Characteristics & $\begin{array}{l}\text { University A } \\
(n=400 ; \%)\end{array}$ & $\begin{array}{l}\text { University B } \\
(n=456 ; \%)\end{array}$ & $\begin{array}{l}\text { Total } \\
(\mathrm{N}=856 ; \%)\end{array}$ \\
\hline \multicolumn{4}{|l|}{ Age $^{a}$ (years) } \\
\hline Mean (SD) & $20.79(1.5)$ & $21.7(1.3)$ & $21.3(1.5)$ \\
\hline Range & $18-28$ & $18-25$ & $18-28$ \\
\hline \multicolumn{4}{|l|}{ Gender } \\
\hline Male & $130(32.5)$ & $139(30.5)$ & $269(31.4)$ \\
\hline Female & $270(67.5)$ & $317(69.5)$ & $587(68.6)$ \\
\hline \multicolumn{4}{|l|}{ Ethnic group } \\
\hline Malay & $53(13.3)$ & $266(58.3)$ & $319(37.3)$ \\
\hline Chinese & $263(65.8)$ & 131 (28.7) & $394(46.0)$ \\
\hline Indian & $35(8.8)$ & $37(8.1)$ & $72(8.4)$ \\
\hline Others $^{\mathrm{b}}$ & $46(11.5)$ & $22(4.8)$ & $68(7.9)$ \\
\hline \multicolumn{4}{|l|}{ Faculty } \\
\hline Arts and Social Sciences & $47(11.8)$ & $88(19.3)$ & 135 (15.7) \\
\hline Business and Law & $109(27.3)$ & $80(17.5)$ & $189(22.1)$ \\
\hline Built Environment, Engineering, Technology and Design & $125(31.3)$ & $101(22.1)$ & $226(26.4)$ \\
\hline Health and Medical Sciences & $88(22.0)$ & $187(41.0)$ & $275(32.1)$ \\
\hline Hospitality, Food and Leisure Management & $31(7.8)$ & - & $31(3.6)$ \\
\hline \multicolumn{4}{|l|}{ Current year of study } \\
\hline Year 1 & $91(22.8)$ & $136(29.8)$ & $227(26.5)$ \\
\hline Year 2 & $133(33.3)$ & $104(22.8)$ & 237 (27.7) \\
\hline Year 3 & $135(33.8)$ & $134(29.4)$ & $269(31.4)$ \\
\hline Year 4 and above & $41(10.25)$ & $82(17.9)$ & $123(14.4)$ \\
\hline \multicolumn{4}{|l|}{ Current health status } \\
\hline Good & $229(57.3)$ & $290(63.6)$ & $519(60.6)$ \\
\hline Satisfactory & $150(37.5)$ & $149(32.7)$ & 299 (34.9) \\
\hline Poor & $21(5.3)$ & $17(3.7)$ & $38(4.4)$ \\
\hline
\end{tabular}

Note: aData were reported as mean (standard deviation, SD), median (interquartile range, IQR) and range. Others included Sinhalese, African, Indonesian, French, Sino, Korean, Pakistani, Kadazan, Kadasandusun, Japanese, Sri Lankan, Punjabi, Seychelloise, Iraqi, Marelius, Maldives, Sikh, Romanian, Burmese, Nepalese, Eurasian, Siamese, Arabian, Kazakhstan, Iban, Bidayuh, and Bugis

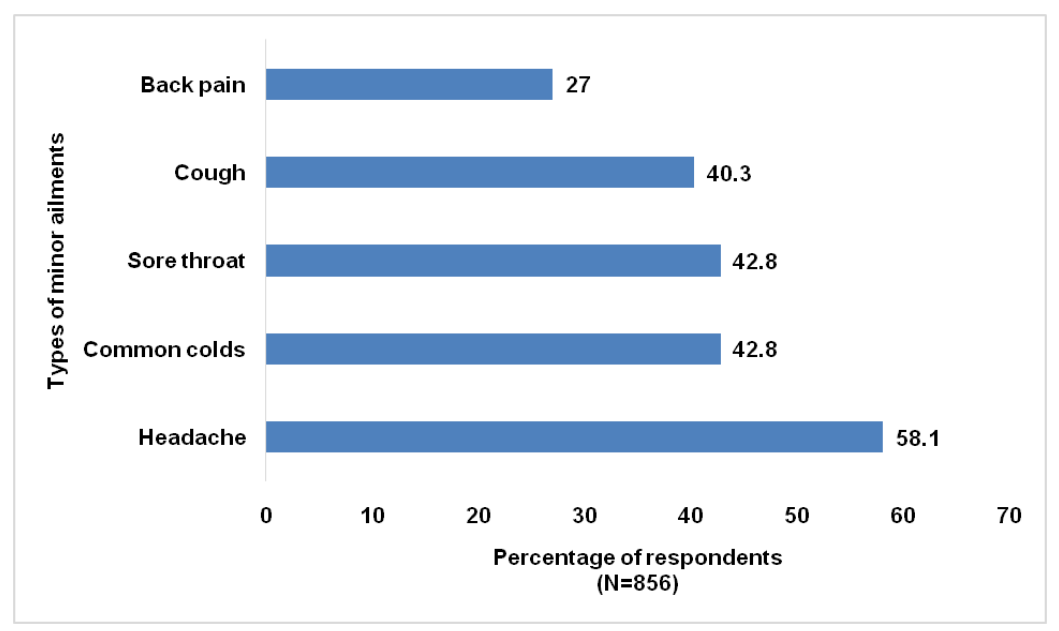

Fig. 1: Five most common minor ailments encountered in the past one month NOTE: The total percentage added up to more than $100 \%$ as one respondent could have more than one minor ailment in the past one month 
Health seeking behavior is referred to as the subsequent action taken by the individuals to relieve the symptoms associated with minor ailments. The respondents took various actions when they encountered different types of minor ailments. The action taken was classified into four main categories; (1) consulted a doctor, (2) self-medication (when a respondent sought advice from a pharmacist, bought medication from a pharmacy or a non-pharmacy shop or used someone else's medication or used traditional medicines), (3) tried home remedies, and (4) ignored the symptoms (including "just rest"). Table 2 shows the action taken in response to the five most common minor ailments.

Table 2: Action taken in response to minor ailments

\begin{tabular}{|c|c|c|c|c|c|}
\hline \multirow[t]{2}{*}{ Action taken } & \multicolumn{5}{|c|}{ Minor ailments frequency $(\mathrm{N}=856 ; \%)$} \\
\hline & $\begin{array}{l}\text { Headache } \\
(n=497)\end{array}$ & $\begin{array}{l}\text { Common cold } \\
(n=366)\end{array}$ & $\begin{array}{l}\text { Sore throat } \\
(n=366)\end{array}$ & $\begin{array}{l}\text { Cough } \\
(n=345)\end{array}$ & $\begin{array}{l}\text { Back pain } \\
(n=231)\end{array}$ \\
\hline See a doctor & $18(3.6)$ & $34(9.3)$ & $46(12.6)$ & $38(11.0)$ & $11(4.8)$ \\
\hline Self-medication & $148(29.8)$ & $131(35.8)$ & $121(33.1)$ & $121(35.1)$ & $29(12.6)$ \\
\hline Try home remedies & $13(2.6)$ & $18(4.9)$ & $45(12.3)$ & $24(6.9)$ & $10(4.3)$ \\
\hline Ignore the symptoms & $318(64.0)$ & $183(50.0)$ & $154(42.1)$ & $162(47.0)$ & $181(78.4)$ \\
\hline
\end{tabular}

In addition, one respondent had a cough and another with sore throat claimed that they quit smoking to alleviate the symptoms. For headache, one of the respondents had head massage to relieve the pain. Six respondents who had back pain reported taking various actions such as the use of hot packs/patches (by three respondents), seek help from a chiropractor, practiced yoga or had a massage (by one respondent each).

For female respondents with period pain, four respondents put hot pack on their abdominal area and another two respondents drank warm water. Three respondents with constipation tried to alleviate the problem by drinking a lot of water, while another three ate more vegetables to ease bowel movement.
Out of 759 medications taken by the respondents, only the name of 396 medications (52.2\%) was given. The most common drug found in the medications used for treating minor ailments was paracetamol (196, 49\%), followed by amylmetacresol and dichlorobenzyl alcohol $(36,9.1 \%)$ which were contents of Strepsils $\AA$ lozenges.

The five main sources of health information used by the respondents are as shown in fig. 2 . Besides these, some respondents referred to books $(100,11.7 \%)$ for the treatment of minor ailments. Two respondents each reported that they treated themselves according to previous experience or obtained information from television. However, 35 respondents (4.1\%) did not seek any health-related information regarding the symptoms and treatment of the minor ailments they encountered.

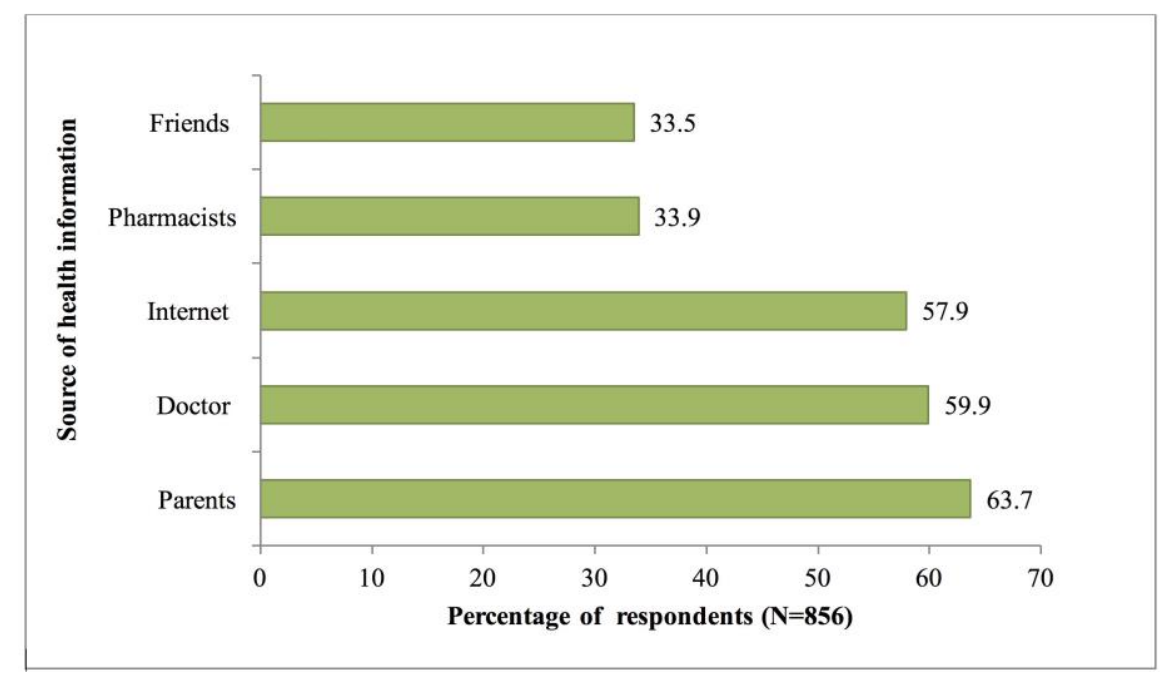

Fig. 2: Sources of health information for treatment of minor ailments

NOTE: The total percentage exceeded $100 \%$ because one respondent could obtain health information from more than one source of the 448 respondents $(52.3 \%)$ who visited a pharmacy for their minor ailments, $34.1 \%$ (292 respondents) requested a particular medication; $33.9 \%(n=290)$ asked advice from the pharmacist; and $22.2 \%(n=190)$ self-selected a specific medication. The total number of requests added up to more than $\mathbf{4 4 8}$ because some of the respondents had more than one type of request at the pharmacy

\section{DISCUSSION}

The mean (SD) age of the respondents was 21 (1.5) years and ranged from 18 to $28 \mathrm{y}$, with $68.6 \%$ being female. These are as expected since the target population are undergraduate students who are usually around $20 \mathrm{y}$ old. In recent years, the population of women attending tertiary education has increased and most universities have more female than male students [13]. More than half of the respondents $(60.6 \%)$ rated their health status as 'good' or 'very good'. This is as expected since the respondents were mainly young adults and generally healthy.

The present study found that the most common minor ailments encountered by university students during a one-month period was a headache, followed by common cold and sore throat. These findings are similar to that of studies in Pakistan and Nepal which also reported headache (69 to $73 \%$ ) and common cold/flu (56 to $66 \%$ ) as the most common minor ailments encountered by university students $[6,7]$. In addition, studies from Egypt and Mekelle indicated that headache (50 to $60 \%$ ) and common cold ( 44 to $70 \%$ ) were the most frequent reason for self-medication among university students $[8,14,15]$.

Back pain is seldom reported as a common minor ailment among university students. This is probably because young adults are less likely to have severe back pain and hence, they are less concerned. In the present study, the prevalence of back pain was $27.0 \%$. Some studies which focused on low back pain among undergraduate students found that more than $40 \%$ of the students with back pain could be associated with psychological conditions of the students 
such as extreme fatigue and depression or the consumption of too much coffee, wrong body posture, place of study and carrying of heavy backpacks $[16,17]$. The authors also indicate that students who are smokers do not do physical exercise and are obese will be more likely to suffer from low back pain.

The present study showed that the main actions taken in response to the five common types of minor ailment were to ignore the symptoms and just rest, followed by self-medication. Peppa et al. [18] found that people would only seek medical care for severe symptoms and chronic illnesses. Therefore, most of the respondents chose to rest at home when they had minor ailments probably because these ailments are often self-limiting and would resolve by itself even without any treatment.

The prevalence of self-medication in the present study (35.8\% for common cold, $35.1 \%$ for cough, $33.1 \%$ for sore throat, $29.8 \%$ for headache and $12.6 \%$ for back pain) is relatively low compared to studies in Oman, Pakistan and Egypt (94\%, 76\%, 62.9\%, respectively) $[5,7,8]$. This could be due to cultural differences between the study population in Malaysia and other countries. The prevalence of self-medication among the general population in Malaysia is higher, $46 \%$ [19]. It has been reported that the younger population tended to care less about their own health conditions compared to elderly people. Previous study reported that younger age groups (18-30 y old) had poor attitude towards medicine use and knowledge of adverse reactions [20].

Paracetamol can be used for pain relief (as an analgesic) and as an antipyretic agent (to relieve fever) for the treatment of minor ailments. Fever is one of the symptoms associated with other minor ailments encountered by the respondents. Therefore, the usage of paracetamol was very predominant among university students due to its wide range of indications such as headache, sore throat, back pain, period pain and fever. Similarly, analgesics were reported as the most common medications used for self-medication in Oman, Nepal and India [5, 6, 21]. Besides these, other studies also reported high usage of analgesics (48 to 82\%) among university students and paracetamol was the most common drug used $[11,22]$. However, the main concern on the high usage of paracetamol is the safety issue and hence, university students should be counseled and cautioned on the maximum daily dose of $4 \mathrm{~g}$ and that overdose of paracetamol can lead to hepatotoxicity.

The respondents in the present study preferred to seek their parents' advice on minor ailments. This result is similar to that of other studies conducted in Nepal, Lebanon and Iran [22-24]. University students are usually young adults who are still under their parents' wings and hence, dependent on their parents for advice. Doctors were the second most common source of information on minor ailments. This indicates that university students have confident in doctors to provide advice on minor ailments. However, studies conducted in other countries showed that pharmacists were the most preferred source of information $[6,8]$. This may be attributed to pharmacy being a relatively newer health care profession in Malaysia compared to the medical profession.

More than a third of the respondents (33.9\%) in the present study consulted a pharmacist on their minor ailments. According to a previous study conducted on the general population in Malaysia, only $27.2 \%$ of the respondents would see a pharmacist for the treatment of minor ailments [19]. This indicates that university students are more aware about the roles of pharmacists in health care than the general population in Malaysia. Similarly, Coelho and Costa [25] found that younger patients in Portugal would seek the pharmacists' advice about their minor health problems. Pharmacists could also recommend the most appropriate medication for their patients based on the symptoms presented and provide counseling on a healthy lifestyle [26-28]. Less than a quarter of the respondents $(22.2 \%)$ in the present study had self-selected a specific medication in the pharmacy to treat their minor ailments. This indicates that a majority of the respondents are aware of the risk of taking medications on their own and preferred to seek the advice of a health care professional.

More than half of the respondents would search for health information via the internet. Similarly, studies in Malaysia and Oman had reported high usage of internet for searching health information $(85.7 \%$ and $89 \%$, respectively) $[29,30]$. This may be attributed to the convenience of retrieving information from the internet as current university students are a new breed of millennials who are digital natives and have been trained to use electronic devices since young age $[30,31]$. However, the concern is the ability of university students to identify reliable sources of information and to interpret them correctly to overcome their health conditions [9].

\section{LIMITATIONS OF THE STUDY}

There are several limitations in this study. The questionnaire used was for self-reporting on the types of minor ailments encountered and action taken. Under-reporting or inaccuracy due to recall bias of the respondents could not be ruled out. Besides, half of the respondents could not remember or did not know the name of the medications they took for treating their minor ailments. Therefore, the types of medications used may be bias towards common medications that the respondents could remember easily. The results of the present study may not be generalized to all university students in Malaysia as only two universities were involved, although these two universities are major universities in Malaysia.

\section{CONCLUSION}

This study documented the common minor ailments encountered by university students, which were headache, common cold, cough, sore throat and back pain. Students usually took a rest at home or did nothing about their minor ailments instead of seeking treatment. However, the most common drug used was paracetamol and the most common source of health care information was from family members instead of health care providers. This calls for health care education on university students to ensure the appropriate management of minor ailments and the safe use of over-the-counter medications. Further studies are required to understand the cause of headache among this population group.

\section{ACKNOWLEDGEMENT}

We would like to express our appreciation to Ms Shazwani Binti Mohd Pakarudin for collecting the data in one of the universities. We are grateful to all the respondents of the present study for making this study possible.

\section{FUNDING}

Nil

\section{AUTHORS CONTRIBUTIONS}

Both authors contributed equally to the design of the study, analysis and interpretation of results, as well as drafting and editing of the manuscript. In addition, LYT collected part of the data for this study and prepared the first draft.

\section{CONFLICT OF INTERESTS}

Both authors declare that they have no conflict of interest.

\section{REFERENCES}

1. Welle Nilsen L, Morken T, Hunskaar S, Granas A. Minor ailments in out-of-hours primary care: an observational study. Scand J Prim Health Care 2010;29:39-44.

2. Fielding S, Porteous T, Ferguson J, Maskrey V, Blyth A, Paudyal $\mathrm{V}$, et al. Estimating the burden of minor ailment consultations in general practices and emergency departments through retrospective review of routine data in North East Scotland. Fam Pract 2015;32:165-72.

3. Peltzer K, Pengpid S, Mohan K. Prevalence of health behaviors and their associated factors among a sample of university students in India. Int J Adolesc Med Health 2014;26:531-40.

4. Pengpid S, Peltzer K, Mirrakhimov E. Prevalence of health risk behaviors and their associated factors among university students in Kyrgyzstan. Int J Adolesc Med Health 2014;26:17585.

5. Flaiti M, Badi K, Hakami W, Khan S. Evaluation of selfmedication practices in acute diseases among university students in Oman. J Acute Dis 2014;3:249-52. 
6. Mehta RK, Sharma S. Knowledge, attitude and practice of selfmedication among medical students. IOSR J Nurs Health Sci 2015;4:89-96.

7. Zafar SN, Syed R, Waqar S, Zubairi AJ, Vaqar T, Shaikh M, et al. Self-medication amongst university students of Karachi: prevalence, knowledge and attitudes. J Pak Med Assoc 2008;58:214.

8. Helal RM, Abou ElWafa HS. Self-medication in university students from the city of Mansoura, Egypt. J Environ Public Health 2017:1-7. DOI:10.1155/2017/9145193

9. Gray NJ, Klein JD, Noyce PR, Sesselberg TS, Cantrill JA. Health information-seeking behavior in adolescence: the place of the internet. Soc Sci Med 2005;60:1467-78.

10. Ghosh S, Vikas V, Gupta A, Chaudhary R. Evaluation of the practice of self-medication among college students in west Uttar Pradesh. Int J Pharm Prof Res 2010;1:14-8.

11. James H, Handu SS, Al Khaja KA, Otoom S, Sequeira RP. Evaluation of the knowledge, attitude and practice of selfmedication among first-year medical students. Med Princ Pract 2006;15:270-5.

12. Klemenc Ketis Z, Hladnik Z, Kersnik J. Self-medication among healthcare and non-healthcare students at University of Ljubljana, Slovenia. Med Princ Pract 2010;19:395-401.

13. Ministry of Education Malaysia. Quick Facts: Malaysia Educational Statistics; 2018. p. 34. Available from: https://www.moe.gov.my/penerbitan/1587-quick-facts-2018malaysia-educational-statistics-1/file. [Last accessed on 30 Aug 2020]

14. Gutema GB, Gadisa DA, Kidanemariam ZA, Berhe DF, Berhe AH, Hadera MG, et al. Self-medication practices among health sciences students: the case of mekelle university. J Appl Pharm Sci 2011;1:183-9.

15. Jalpa Suthar, Patel Shrina P, Solanki Riddhi N. Knowledge, attitude, and practices of self-medication among the students of the private university. Asian J Pharm Clin Res 2020;13:104-9.

16. Aggarwal N, Anand T, Kishore J, Ingle GK. Low back pain and associated risk factors among undergraduate students of a medical college in Delhi. Educ Health, 2013;26:103.

17. Gilkey DP, Keefe TJ, Peel JL, Kassab OM, Kennedy CA. Risk factors associated with back pain: a cross-sectional study of 963 college students. J Manipulative Physiol Ther 2010;33:88-95.

18. Peppa M, Edmunds WJ, Funk S. Disease severity determines health-seeking behaviour amongst individuals with influenzalike illness in an internet-based cohort. BMC Infect Dis 2017; 17:238.
19. Institute for Public Health and Ministry of Health Malaysia. National Health and Morbidity Survey 2015 Healthcare Demand Volume III; 2015. p. 18. Available from: https://www.moh.gov.my/moh/resources/NHMS2015VolumeIII.pdf. [Last accessed on 30 Aug 2020]

20. Lim KK, Teh CC. A cross-sectional study of public knowledge and attitude towards antibiotics in Putrajaya, Malaysia. South Med Rev 2012;5:26.

21. Sontakke SD, Bajait CS, Pimpalkhute SA, Jaiswal KM, Jaiswal SR. Comparative study of evaluation of self-medication practices in First and Third Year medical students. Int J Biol Med Res 2011;2:561-4

22. Sarahroodi S, Maleki Jamshid A, Sawalha AF, Mikaili P, Safaeian L. Pattern of self-medication with analgesics among Iranian University students in central Iran. J Fam Community Med 2012;19:125-9.

23. Bhattarai N, Basyal D, Bhattarai N. Self medication practice among undergraduate pharmacy students in Kathmandu Valley, Nepal. Int J Pharm Sci Res 2014;5:737-46.

24. El Kahi HA, Rizk GA, Hlais SA, Adib SM. Health-care-seeking behaviour among university students in Lebanon. East Med Health J 2012;18:598.

25. Coelha RB, Costa FA. Impact of pharmaceutical counseling in minor health problems in rural portugal. Pharm Pract 2014;12:451.

26. Porteous T, Ryan M, Bond C, Watson M, Watson V. Managing minor ailments; the public's preferences for attributes of community pharmacies. A discrete choice experiment. PLoS One 2016;11:1-15.

27. Mahmudah RL, Ikawati Z, Wahyono D. A qualitative study of perspectives, expectations and needs of education in chronic obstructive pulmonary disease (COPD). Int J Curr Pharm Res 2017;9:32-5.

28. Sauriasari R, Sakti RM. Impact of a pharmacist-led patient education initiative on glycemic control of patients with type 2 diabetes mellitus: a single-center experience in West Jakarta, Indonesia. Int J Appl Pharm 2018;10:252-6.

29. Sultan K, Joshua VR, Misra U. Health information-seeking behaviour of college students in the sultanate of Oman. Khyber Med Univ J 2017;9:8-14.

30. Yilma TM, Inthiran A, Reidpath D. College students from developing countries: Where do they get health information. In: Proceedings of the $2^{\text {nd }}$ SIGIR workshop on Medical Information Retrieval (MedIR); 2016

31. Varghese Sneha Suja, Sneha Dutta, Ann Mary Swaroop. Knowledge and perceptions of self-medication practices in an urban community. Asian J Pharm Clin Res 2019;12:42-5. 